\title{
Identidade, modernidade e escrita eclesiástica em tempos de Reforma Ultramontana: apontamentos teóricos a partir das contribuições de Paul Ricoeur e Kathryn Woodward
}

\author{
Tiago Pires*
}

\begin{abstract}
Resumo
Este artigo objetiva analisar as formas de produção da identidade na modernidade por meio das construções simbólicas presentes nas narrativas memorialistas redigidas pela Igreja Católica, em fins do século XIX e início do XX. Discute-se alguns caminhos teóricos delineados por Paul Ricoeur e Kathryn Woodward, para se compreender como tais identidades são construídas e projetadas, seguindo um projeto teológico-político de fortalecimento da instituição pautado na elaboração de sacerdotes exemplares e santos. Busca-se relacionar tais premissas teóricas com o estudo da escrita eclesiástica no Brasil, particularmente em Minas Gerais, utilizada para consolidar o processo de reforma ultramontana em voga no catolicismo no Brasil. Para tanto, utilizamos como objeto de análise a figura de um sacerdote constituído como exemplar pelos periódicos oficiais da Diocese de Mariana, o padre e reitor do seminário, João Batista Cornagliotto (1855-1902).
\end{abstract}

Palavras-chave: Identidade; Escrita eclesiástica; Catolicismo; Ultramontanismo.

O advento da modernidade ${ }^{1}$ trouxe consigo mudanças na vivência e nas formas de atuação do sujeito, configurando inteligibilidades do mundo independentes das premissas religiosas. Essa pluralidade de interpretações destituiu a Igreja Católica de seu estatuto central no fornecimento de sentido à existência humana, criando um perfil cada vez mais autônomo do sujeito em relação à instituição religiosa. A partir do século XVIII, sobretudo, por meio das afrontas postas pelo racionalismo das Luzes, o catolicismo empenhou-se num embate crucial pela permanência de sua mensagem de fé, tão questionada pela filosofia cética do século seguinte (SESBOUÉ; THEOBALD, 2006; VERGOTE, 2002).

\footnotetext{
*Doutorando em História pela Universidade Estadual de Campinas (UNICAMP).

${ }^{1}$ Consideramos a modernidade como emergente no século XVI, porém com diversos desdobramentos (cascatas) ao longo dos séculos, como define Gumbrecht: "como cascatas, esses conceitos diferentes de modernidade parecem seguir um ao outro numa sequencia extremamente veloz, mas, retrospectivamente, observa-se também como se cruzam, como os seus efeitos se acumulam e como eles interferem mutuamente numa dimensão (difícil de descrever) de simultaneidade" (GUMBRECHT, 1998, p. 9). Já os termos "modernidade tardia", "nossa modernidade" e "pós-modernidade" se referem a um recorte mais atual, localizado a partir das décadas de 1960 e 1970.
} 
A modernidade postulou diversos desafios ao catolicismo, na medida em que suas premissas constituíram "sociedades de mudança constante, rápida e permanente", diferentemente das sociedades tradicionais pautadas no passado e na veneração da experiência das gerações anteriores (HALL, 2000, p. 14). Além disso, a modernidade radicalizou a dimensão reflexiva da vivência, do mundo e do sujeito, inspirada na racionalidade e na ética política, mais do que nos princípios religiosos que, apesar de não desaparecerem, perderam a primazia de fornecimento de sentido à vida pessoal e social (HALL, 2000; GUMBRECHT, 1998).

Na modernidade, o passado é visto como algo a ser superado, tornando o futuro o local do progresso, da melhoria, alcançados por meio de uma projeção (horizonte de expectativa) elaborada no próprio presente (espaço de experiência). A experiência temporal moderna substituiu a concepção cristã medieval, na qual o passado era o gerador central de sentido à existência, e o futuro escatológico, o lugar do medo, da incerteza, pois era marcado pela evidência do fim dos tempos e do consequente Juízo Final (KOSELLECK, 2006, p. 31). Nesse sentido, a estrutura moderna de pensamento e de sociedade, e mesmo de sujeito, constitui-se como um desafio para o catolicismo. Como manter vigente uma mensagem de fé inspirada na tradição, num passado remoto da Revelação e da Encarnação, sendo que os princípios modernos eram encaminhados para a direção contrária de tais diretrizes católicas?

"As transformações associadas à modernidade libertaram o indivíduo de seus apoios estáveis nas tradições e nas estruturas" (HALL, 2000, p. 25), descentrando as formas de produção de sentido e acentuando a pluralidade e a fragmentação identitária. Em uma cultura moderna destituída de um sentido existencial único e central, a procura por uma identidade se torna mais valorativa, não somente no âmbito religioso, e pode estar atrelada a uma busca de sentido para a vivência ou a uma disputa de poder para legitimar uma determinada posição ou prática social. A legitimação de projetos políticos, individuais ou coletivos se pauta na busca e na consolidação de identidades unificadas, normalmente encontradas num passado que valida o seu caráter de "verdadeira" identidade (WOODWARD, 2000, p. 12).

Na modernidade, o discurso de fé como ordenador da vivência humana é processualmente substituído pela ética política, em contraposição à piedade e à moral religiosa católica (CERTEAU, 2008, p. 169). Nesse momento conflituoso e desprovido de um sentido existencial único, emergem, sobretudo no campo discursivo, variadas 
modalidades da escrita eclesiástica como formas de expressão e fornecimento de sentido à vida humana, aliadas à construção/reafirmação de uma identidade católica unificada e universalizante. As discussões sobre a construção simbólica da identidade por meio das narrativas eclesiásticas tornam-se significativas, uma vez que os "discursos e os sistemas de representação constroem os lugares a partir dos quais os indivíduos podem se posicionar e a partir dos quais podem falar." (WOODWARD, 2000, p. 17). No bojo de tais discussões, objetivamos analisar como a Igreja Católica utilizou distintas modalidades narrativas ${ }^{2}$ como ferramentas de produção de identidade, principalmente para a própria instituição, almejando consolidar um projeto de reforma ultramontana, voltado para a modificação das práticas eclesiásticas e para o fortalecimento da instituição, diante da cultura moderna oitocentista e do início do século XX. Apontaremos, a seguir, alguns caminhos teóricos para se analisar esse processo de construção identitária para, posteriormente, nos atermos às maneiras com que a Igreja construiu e manuseou tais identidades exemplares, elaboradas, sobretudo, por meio de narrativas memorialistas.

\section{Como construir sacerdotes exemplares? Uma discussão a partir da produção da identidade}

A questão que nos faz problematizar as discussões sobre a identidade na pósmodernidade, postuladas por autores como Stuart Hall (2000) e Kathryn Woodward (2000), pode-se resumir nas seguintes indagações: é possível pensarmos numa identidade unificada e fixa ao longo da história? Será que as identidades cambiantes, fragmentadas e plurais são características apenas da nossa contemporaneidade ${ }^{3}$ ? Propomos uma resposta breve, mas que será analisada com mais precisão ao longo deste tópico, sobretudo a partir da hermenêutica do si elaborada por Paul Ricoeur (1991). A identidade e o sujeito podem ser mais fluidos e plurais no contexto da pós-modernidade, ou "modernidade líquida", como conceitua o sociólogo Zygmunt Bauman (2001). Porém, eles não se tornaram fragmentados, plurais e mutáveis especificamente nesse momento. Um sujeito unificado, como apontou Lacan, é uma ilusão (WOODWARD, 2000, p. 63).

\footnotetext{
${ }^{2}$ Neste texto, analisaremos mais a fundo as narrativas presentes nos jornais oficiais da Diocese de Marina, a saber, o jornal O Viçoso (1893/6) e o Boletim eclesiástico (1902).

${ }^{3}$ Ou seja, da nossa modernidade (ou pós-modernidade, como prefere Stuart Hall).
} 
Ao tratar da nossa modernidade ${ }^{4}$, Stuart Hall demarca um momento de ruptura no qual "as velhas identidades, que por tanto tempo estabilizaram o mundo social, estão em declínio, fazendo surgir novas identidades e fragmentando o indivíduo moderno, até aqui visto como um sujeito unificado". O autor caracteriza a crise de identidade atual devido ao deslocamento e à fragmentação dos quadros de referência que outrora "davam aos indivíduos uma ancoragem estável no mundo social." (HALL, 2000, p. 7). Apesar de Hall considerar a historicidade da noção de sujeito ao longo da história moderna, dividindo-o em três concepções de identidade (sujeito do Iluminismo, sociológico e pós-moderno), o autor confere à última categoria identitária a emergência do indivíduo plural, fragmentado e instável (HALL, 2000, p. 12).

O sujeito pós-moderno não tem uma identidade fixa, essencial ou permanente. Ele "assume identidades diferentes em diferentes momentos, identidades que não são unificadas ao redor de um 'eu' coerente" (HALL, 2000, p. 13). Da mesma forma que Ricoeur e Woodward, Hall reconhece a impossibilidade de uma identidade unificada desde o nascimento até a morte de uma pessoa, ressaltando que tal unidade só é possível por meio de uma narrativa do eu. Contudo, Hall e Woodward realizam tais afirmações, tendo, como contexto de análise, a pós-modernidade, diferente de Ricoeur, que elabora tal afirmativa numa perspectiva ontológica e fenomenológica, na qual o sujeito é sempre fragmentado e plural. Para o filósofo francês, o que varia são os níveis dessa instabilidade. Como pensar, portanto, um sujeito cindido ${ }^{5}$ em outros contextos, que não o pós-moderno?

A teoria narrativa de Paul Ricoeur sobre a construção de si e sobre a identidade narrativa nos proporciona uma maneira de pensar o sujeito e a identidade como fragmentados não apenas na contemporaneidade, ainda que hoje tais premissas estejam mais exacerbadas. Nesse sentido, as discussões acerca da identidade narrativa desenvolvidas por Ricoeur nos parecem um complemento plausível para pensarmos o sujeito e a construção da identidade do sacerdote reformado como instâncias fragmentadas, mesmo não pertencendo ao recorte da pós-modernidade.

\footnotetext{
${ }^{4}$ Diferente de Zygmunt Bauman (2001) e Anthony Giddens (1991), Stuart Hall (2000) opta por utilizar a categoria de pós-modernidade, o que seria para Giddens e Bauman não um "após a modernidade", mas uma radicalização dos princípios modernos emergidos no século XIX. No presente texto, não entraremos em tal discussão conceitual, mantendo a caracterização dada pelos autores citados, porém considerando o advento da modernidade no século XVI.

${ }^{5}$ Chamamos de "cindido" esse sujeito plural e fragmentado.
} 
Em sua obra $\mathbf{O}$ si-mesmo como um outro, Paul Ricoeur opta por discutir a questão da identidade, sobretudo em sua dimensão narrativa, a partir da categoria de "simesmo" (ipseidade), haja vista que a partícula reflexiva "si" pressupõe uma reflexão sobre o sujeito, e não um "eu" pronto, dado de antemão. Tal vertente interpretativa se contrapõe à noção do "eu” empírico ou transcendental, "em que o 'eu' seja colocado independentemente, isto é, sem confrontação com o outro, ou relativamente, requerendo a egologia o complemento intrínseco da intersubjetividade." (RICOEUR, 1991, p. 14). O "eu" pode ser pensado como uma categoria de identificação que o sujeito inscreve em um discurso, no momento da ação, como, por exemplo, quando alguém diz "eu fiz isso" ou "eu sou o responsável por essa ou aquela ação" (RICOEUR, 1991, p. 29). Já os desdobramentos dessa ação são incapazes de serem definidos pelo "eu” inicial da ação.

A partícula reflexiva "si" permite pensar o indivíduo e sua identidade, uma vez que ambos só podem ser imaginados por meio de uma reflexão do "quem sou eu" e da inevitável relação com o outro. A hermenêutica do si que Paul Ricoeur empreende se distancia de uma concepção essencialista do eu e da identidade, bem como afirma a existência de um sujeito da ação. Ricoeur afasta sua concepção de sujeito da radicalidade do cogito cartesiano e da inexistência do "eu" em Nietzsche, para perceber o si-mesmo como uma ação reflexiva do "eu" (o si), e a partir daí pensar a identidade em suas dimensões cambiantes e permanentes. Uma diferença separa a "hermenêutica do si das filosofias do cogito. Dizer "si" não é dizer "eu". O "eu" se opõe ou é deposto. O "si" está implicado a título reflexivo nas operações cuja análise precede a volta para ele próprio." (RICOEUR, 1991, p. 30). Ricoeur opta pelo "si-mesmo" ao invés do "eu", da "subjetividade" e do cogito cartesiano.

Na perspectiva da hermenêutica do "si" desenvolvida por Ricoeur, a identidade pessoal pode ser pensada em duas instâncias diferentes, ainda que dialógicas: a identidade-idem e a identidade-ipse (RICOEUR, 1991, p. 13). Quando se inscreve o “eu” numa ação, “eu fiz isso", por exemplo, a questão identitária não é problemática. A ação não pressupõe, a priori, a determinação da identidade, pois ela é circunstancial. "É com a questão da permanência no tempo que a confrontação entre nossas duas versões da identidade [idem e ipse] ocasiona, pela primeira vez, um verdadeiro problema." (RICOEUR, 1991, p. 140). É quando tentamos caracterizar "quem sou eu" que a identidade se torna complexa de ser definida, pois tentaremos buscar, em diferentes dimensões, sobretudo em nossa história de vida, a caracterização/construção do "si”, o pensar sobre "si" e sobre quem somos ou gostaríamos de ser. Tendo em vista que o 
sujeito da ação é definido pela elocução circunstancial "eu", é no momento em que começamos a refletir sobre "quem nós somos" que percebemos a emergência do sujeito cindido, fragmentado e plural.

Segundo Ricoeur, ao "falarmos de nós mesmos, dispomos de fato de dois modelos de permanência no tempo, que resumo por dois termos ao mesmo tempo descritivos e emblemáticos: 'o caráter' e a 'palavra considerada'.” (RICOEUR, 1991, p. 143). No caráter, o idem e o ipse tendem a coincidir, já na palavra considerada, a ipseidade liberta-se da mesmidade, pois depende de um fator externo: o compromisso ético firmado com o outro. O caráter "designa o conjunto das disposições duráveis 'com que' reconhecemos uma pessoa.", sendo que ele pode ser formado por meio de processos conscientes ou inconscientes. (RICOEUR, 1991, p. 146).

Ao pensar o papel do inconsciente na formação do sujeito, Ricoeur se embasa nas proposições freudianas, porém, afasta-se um pouco delas ao ressaltar a capacidade humana de pensar sobre si, eliminando a força que o inconsciente tem nas teorias psicanalíticas (PIVA, 1999, p. 228). A formação consciente da identidade-idem ocorre através da interlocução com o outro, com os valores, normas, ideais, modelos, heróis, nos quais um indivíduo ou comunidade se reconhece. Ao elegermos uma identificação externa, um padre exemplar (ou santo), por exemplo, iniciamos um processo de manutenção de si, ou seja, manutenção daquela identidade na qual optamos por nos identificar e que, consequentemente, passa a constituir nosso caráter. Nesse processo, "um elemento de lealdade, de lealismo, incorpora-se assim ao caráter e o faz transformar-se em fidelidade, portanto, à manutenção de si." (RICOEUR, 1991, p. 147).

Existe, além do caráter, outro modelo de permanência no tempo, no qual Ricoeur denomina de "palavra considerada". Tal dimensão se embasa numa perspectiva ética firmada com a alteridade. O sujeito tem que cumprir com a promessa que fez ao outro. A ética na manutenção de si da promessa feita à alteridade não necessariamente precisa concordar com a identidade-idem (caráter). Logo, a ipseidade se torna livre da mesmidade na palavra considerada, pois a ética é mais forte que o compromisso com o caráter. A mesmidade e a ipseidade não existem separadamente, porém, não são dimensões simétricas, a não ser na narrativa, em que tais instâncias assumem um grau maior de equiparação (RICOEUR, 1991, p. 148-149).

A análise ricoeuriana sobre a identidade narrativa recai sob a dimensão tensional na formação das identidades, que transita entre a ipseidade e a mesmidade, entre 
características permanentes e outras circunstanciais. A resposta à pergunta "quem eu sou" não se faz por meio de uma verbalização da verdade sobre si, mas a partir de uma "atestação de si”, que se liga à confiança, à credibilidade. A narrativa é um meio de atestação de si na qual é tecida uma harmonia entre o "caráter" (o que permanece) e a "palavra considerada" (mutável, pois depende da relação com o outro). Em muitas narrativas, o si procura a sua identidade ao longo da história de uma vida. Isso não significa dizer que a narrativa, necessariamente, cria uma identidade única, fixa e imutável, mas que ela é capaz de melhor harmonizar a simetria entre o idem e o ipse, organizando a mutabilidade da vida e da identidade em uma narrativa coesa, sem precisamente excluir tais dimensões tencionais.

Todo ato narrativo, tanto no formato oral quanto escrito, pressupõe um diálogo entre história e ficção. No momento em que as ações, os acontecimentos e as pessoas são transpostos para a narrativa, a contingência e as contradições da vivência humana são transformadas numa história coesa e com sentido. Quando se narra a história de uma vida, por exemplo, o sujeito olha para o passado a partir de um ponto de sua existência, já sabendo como algo irá terminar, encadeando os acontecimentos de maneira a representar e construir um si-mesmo pré-estabelecido e projetável. As vidas humanas se tornam mais inteligíveis quando postas na forma narrativa, num amálgama entre história e ficção, elaborada no formato de uma trama (drama, romance, etc). Para Ricoeur, "a compreensão de si é uma interpretação; a interpretação de si, por sua vez, encontra na narrativa, entre outros signos e símbolos, uma mediação privilegiada" fazendo da história de uma vida uma ficção histórica, "entrecruzando o estilo historiográfico das biografias com o estilo romanesco das autobiografias imaginárias” (RICOEUR, 1991, p. 138). Em muitas narrativas, é pela escala de uma vida que se procura uma identidade, haja vista que é difícil pensar a identidade de um sujeito a partir de um acontecimento, de uma única ação.

Atuamos de acordo com as opções simbólicas e sociais que estão disponíveis, o que Bourdieu chama de "campos sociais" (família, grupos de colegas e trabalho, instituições educacionais ou partidos políticos). Não somos a mesma pessoa o tempo todo. Assumimos diferentes identidades de acordo com os campos sociais em que estamos e agimos (WOODWARD, 2000, p. 30). Entretanto, a identidade narrativa consegue realizar uma "configuração" entre ipseidade e mesmidade, produzindo uma síntese do heterogêneo, exatamente porque se transpõe para o nível narrativo que, ao misturar o histórico (factual) com o imaginado (ficção, poética), é capaz de produzir 
uma vida com sentido, com uma identidade mais sólida do que no campo da vivência (RICOEUR, 1991, p. 169). A identidade narrativa põe "em equilíbrio os traços imutáveis que esta deve à ancoragem da história de uma vida num caráter e o que tendem a dissociar a identidade do si da mesmidade do caráter." (RICOEUR, 1991, p. 148). A narrativa é capaz de harmonizar os possíveis conflitos de interesse entre as diferentes identidades assumidas por um mesmo indivíduo.

Ao mesmo tempo em que combina fabulação com experiência de vida, a narrativa é capaz de projetar uma identidade, uma vez que se embasa num "projeto existencial", que não é apenas fruto da vivência do autor, mas um processo de construção do sujeito no ato narrativo, destinado ao presente e ao futuro. A narrativa é constituída pelo sujeito, ao mesmo tempo em que o constitui, criando uma ética própria. $\mathrm{O}$ ato narrativo de formação da identidade e de fornecimento de sentido à existência individual faz parte da necessidade ontológica do sujeito, tendo em vista que "É precisamente em razão do caráter evasivo da vida real que temos necessidade do auxílio da ficção para organizar esta última retrospectiva extemporânea" (RICOEUR, 1991, p. 191-192; SPERBER, 2009).

Em diálogo com a hermenêutica e com uma fenomenologia "menos clássica", entre a teoria da ação e a teoria narrativa, Ricoeur entende o sujeito e sua identidade como instâncias fragmentárias, não se restringindo à conjuntura pós-moderna para acomodar tais instâncias. O sujeito é cindido em qualquer momento da história. É o grau da fragmentação e pluralidade que varia historicamente e de acordo com as dimensões em que o sujeito atua, se pensa e se inscreve. Talvez as obras de santo Agostinho, da qual Ricoeur foi um assíduo leitor, e as de cunho teológico-hermenêutico, tenham permitido a percepção do sujeito fragmentado e instável fora do contexto pósmoderno. Os relatos bíblicos neotestamentários, a exemplo das cartas de Paulo ( $\mathrm{Rm} 7$, 19-20) ${ }^{6}$, ou das Confissões, de santo Agostinho, mostram-nos um sujeito cindido não apenas pela sua fragmentação identitária, mas por suas paixões ou, na concepção cristã, pelo pecado. A construção das identidades sacerdotais em tempos de reforma católica em fins do século XIX e início do XX, sobretudo em sua dimensão narrativa, pode ser interpretada a partir da chave de leitura proposta nesta breve discussão, intercruzando os pressupostos teóricos delineados por Woodward e, principalmente, por Ricoeur.

\footnotetext{
6 "19. Com efeito, não faço o bem que eu quero, mas pratico o mal que não quero. 20. Ora, se eu faço o que não quero, já não sou eu que estou agindo, e sim o pecado que habita em mim." A Bíblia de Jerusalém (1996).
} 


\section{Para lembrar e seguir: a produção da identidade católica ultramontana na escrita eclesiástica}

Quando os movimentos sociais reivindicam uma identidade - de gênero, sexual, étnica, religiosa -, eles não estão lutando somente por uma representação destinada à produção de sentido à existência, mas por uma reafirmação identitária voltada para a defesa de empreendimentos políticos e sociais. (WOODWARD, 2000, p. 33-35). "Essa identidade torna-se, assim, um fator importante de mobilização política. Essa política envolve a celebração da singularidade cultural de um determinado grupo, bem como a análise de sua opressão específica." (WOODWARD, 2000, p. 34). Tais construções identitárias devem, para concretizar um projeto político, desdobrar-se no campo das práticas, no campo social. Para tanto, algumas se apoiam em afirmações essencialistas, enquanto outras se apoiam em perspectivas não-essencialistas.

As identidades são vistas não somente como características simbólicas voltadas para a simples manutenção da vida e do sentido existencial. Elas são criadas, modificadas, reafirmadas ou excluídas pautando-se em interesses, em relações de poder e em projetos políticos e pessoais. Elas também procedem do investimento inconsciente em determinadas posições, lembrando que esse inconsciente é formado não por uma essência, mas por meio da conjuntura sociocultural, na qual o individuo se desenvolveu (WOODWARD, 2000, p. 55). Nesse sentido, a escrita eclesiástica em tempos de reforma ultramontana deve ser pensada em sua função de produção de sentido para a própria instituição e como uma maneira de construir identidades a serem seguidas pelo clero, utilizando identidades unificadas como ferramenta de disputa de poder, de afirmação da fé e difusão de modelos eclesiais a serem seguidos. As identidades são produzidas a partir de diferentes fatores: simbólicos, materiais, sociais, inconscientes. Apesar de eles estarem interligados, nossa análise recai sob a dimensão simbólica, mais especificamente sob as narrativas memorialistas presentes nos periódicos oficiais da Diocese de Mariana, em fins do oitocentos e início do século XX.

Objetivamos compreender o processo de construção da identidade de um sacerdote exemplar, em tempos de reforma ultramontana em Minas Gerais, particularmente, na Diocese de Mariana, que se vincula, ao mesmo tempo, à produção da memória desse sujeito. Para tanto, utilizamos como objeto de análise a figura de um sacerdote constituído como exemplar pelos periódicos oficiais de tal diocese, o padre e 
reitor do seminário João Batista Cornagliotto, no recorte de 1855 a $1902^{7}$. Apesar do sacerdote exemplar se diferenciar do santo canonizado ${ }^{8}$, ambos deveriam estar em consonância com a concepção ideal de sacerdote do contexto eclesial e sociocultural para se tornarem modelos a serem seguidos. Além disso, ambos tornavam-se exemplares e eram construídos e divulgados por meio da escrita.

O processo de reforma ultramontana na Diocese de Mariana, durante o século XIX e início do XX, é entendido como uma tentativa de modificação de práticas e posturas do clero e dos fiéis, bem como uma estratégia de fortalecimento da instituição perante os desafios postulados pela cultura moderna. As diretrizes teológico-políticas desse processo se relacionavam com as premissas romanas delineadas pelo pontífice e, em âmbito local, com as proposições dos bispos. Um modelo de Igreja e sacerdote não foi rapidamente encontrado no contexto cultural brasileiro do século XIX (OLIVEIRA, 2010). Portanto, fez-se necessária a construção, sobretudo no campo discursivo, das memórias e identidades dos sacerdotes exemplares, aqueles que exerceram seu ministério como agentes da romanização e que podiam ser utilizados como referenciais para o clero, haja vista que estavam em consonância com o que era esperado de um padre reformado. A construção da memória e da identidade eclesiástica, a partir da escrita, constitui-se como parte do projeto eclesial ultramontano, voltado para o fortalecimento da Igreja Católica perante a sociedade moderna oitocentista e em constante processo de laicização.

Os projetos de reforma do catolicismo no Brasil, ao longo dos séculos XIX e $\mathrm{XX}$, se inspiraram no pensamento teológico-político ultramontano ${ }^{9}$, delineado

\footnotetext{
${ }^{7}$ Período de seu reitorado na Diocese de Mariana. Alguns autores consideram o início de seu reitorado no ano de 1856, devido à oficialização da posse do cargo.

${ }^{8}$ Tendo em vista que o santo canonizado é também um modelo sacerdotal construído e veiculado pela Igreja Católica para ser seguido como exemplar e transmitir o sentido da fé cristã. Contudo, o procedimento institucional de canonização do santo é diferenciado, e envolve um processo específico de produção, além de denotar a autoridade pontifícia, haja vista que é o papa que legitima o santo, desde o ano de 1234. (WOODWARD, 1992, p. 17-18).

9 “Até o século XIX não se falava em ultramontanismo, mas em ultramontanos, "defensores da concepção que se tem do papado do outro lado dos Alpes", unidos a uma fidelidade às diretrizes romanas na constituição de uma identidade católica supranacional. Podemos falar, mais especificamente, de um romanismo dos séculos XVII e XVIII que se desenvolve processualmente, desdobrando-se no ultramontanismo oitocentista, mais combativo e apologético em resposta ao avanço das teorias anticatólicas. Os princípios são parecidos, porém no catolicismo oitocentista "o acento é posto na nota da unidade, mas segundo uma interpretação jurídica: a Igreja é fundada no papa que é o princípio de sua unidade". No campo da espiritualidade pode-se falar de uma piedade ultramontana, voltada para a reapropriação das tradições locais e populares e do incentivo às devoções ao Santíssimo Sacramento, ao Sagrado Coração e à Virgem, "num sentido 'amável e exteriorizado (Gadille, 1985), mas também num
} 
inicialmente no âmbito romano, no início dos oitocentos. Seu objetivo consistiu no fortalecimento da fé católica, enfraquecida desde o século XVIII com o racionalismo das Luzes e com a filosofia cética do século seguinte. A unificação da identidade católica, bem como a sua universalização, foi uma das estratégias de fortalecimento inspiradas nos escritos papais e nos cânones do catolicismo, sobretudo no Concílio Tridentino. Foi esse movimento de unificação doutrinal e identitária que ocorreu na Europa, a partir de meados do século XVIII e ao longo do XIX, exatamente em um dos momentos mais cruciais do embate entre o catolicismo e a cultura moderna. No Brasil, é possível encontrar em fins do século XVIII e início do XIX indícios dessa identidade reformada?

O processo de reforma do catolicismo no Brasil estava associado, em grande parte, à vinda de missionários estrangeiros às dioceses locais. O clero vindo da Europa era considerado pelo imaginário eclesiástico brasileiro como exemplar, pois deveria estar em maior consonância com o catolicismo ultramontano. Os padres envolvidos na política ou com ideais liberais, desviados dos preceitos romanos, algo recorrente no século XVIII e XIX no Brasil, não eram bons exemplos nem referenciais para a Igreja Católica e para os fiéis (OLIVEIRA, 2010). Dessa forma, como criar uma identidade católica unificada e universal a partir dos modelos sacerdotais existentes no Brasil? A escrita eclesiástica oitocentista foi uma das respostas a essa questão. Foi preciso, no século XIX e na primeira metade do século XX, criar representações de sacerdotes exemplares, preservando a memória e consolidando a identidade dos "bons pastores", daqueles padres que se tornaram agentes da romanização e que se constituíram como modelos do perfil clerical desejado pela Igreja Católica nesse contexto. A reforma também foi executada no campo discursivo, devendo desdobrar-se na modificação das práticas eclesiásticas.

Os modelos desviantes do clero eram utilizados como contraponto e, portanto, como reforço para a construção do padre exemplar, tendo em vista que a própria construção da identidade é marcada pela diferença (WOODWARD, 2000, p. 9). "A marcação da diferença é crucial no processo de construção das posições de identidade", e é produzida por meio de sistemas simbólicos, como a linguagem e a escrita (WOODWARD, 2000, p. 39). Se existe um clero exemplar, romanizado, é porque também existe um sacerdote que se opõe a esse modelo. Construir uma identidade

espírito de penitência e de reparação.". Junto a isso, uma revalorização dos santos taumaturgos e do culto das relíquias e objetos afins." (PIRES, 2012, p. 21). 
clerical reformada pressupunha se opor ao clero liberal, ao envolvido com a política, ao não santo. Apesar de tal oposição estar implícita na narrativa eclesiástica, não era tão recorrente a inclusão dos sacerdotes "desviantes" na escrita eclesiástica ${ }^{10}$, pois não citálos era uma maneira de preservar a memória impecável da instituição. Nessa perspectiva, a escrita eclesiástica nesse recorte, ao mesmo tempo em que criava a memória de seus padres exemplares, também construía a identidade reformada almejada, até então pouco recorrente em solos brasileiros.

Os jornais eclesiásticos e os opúsculos de cunho (auto)biográficos produzidos na Diocese de Mariana em fins do século XIX e início do XX, por exemplo, nos mostram esse processo de construção da memória e da identidade dos padres exemplares, que deveriam ser lembrados tanto para exaltar seus feitos quanto para criar modelos a serem seguidos. A construção da memória eclesiástica é também uma prática de elaboração da identidade clerical. Na medida em que os órgãos oficiais da Diocese de Mariana ${ }^{11}$ veiculavam os feitos positivos do padre Cornagliotto, ele aos poucos se constituía como exemplar. Não que ele tenha sido, na visão de seus contemporâneos eclesiásticos, um clérigo perfeito. Porém, a memória e identidade a serem deixadas, e consequentemente seguidas pelos padres da diocese, deveriam ser "sem rugas", "imaculadas".

A escrita eclesiástica, nessa perspectiva, foi também performática, construtiva de um protótipo sacerdotal a ser seguido no campo das práticas. Entretanto, a história de vida do sujeito e a sua identidade só adquirem um sentido exemplar na sua forma narrativa, na qual ocorre um processo de harmonização entre a mesmidade e a ipseidade, criando a ilusão de um sujeito e de uma identidade unificados (RICOEUR, 1991, p. 176; PIVA, 1999, p. 220). Não existe, ao longo da existência do indivíduo, uma identidade fixa, um sujeito completamente coerente com o seu suposto "si", pois a dimensão da vivência é caótica, fragmentada e cambiante. Dessa forma, não há uma identidade e um sacerdote exemplar (ou santo) fora da narrativa. Tais pressupostos narrativos dialogam, em certo sentido, com o estilo hagiográfico, na medida em que

O extraordinário e o possível se apoiam um no outro para construir uma ficção posta aqui a serviço do exemplar. [...] sob a forma de um relato, apresenta uma função de 'gratuidade' que se encontra igualmente no texto e no seu uso. É uma poética de sentido. (CERTEAU, 2008, p. 270-271).

\footnotetext{
${ }^{10}$ Com exceção das cartas, que muitas vezes denunciavam tais padres irregulares.

${ }^{11}$ Utilizamos como objeto de análise reportagens sobre o padre Cornagliotto presentes no jornal O Viçoso (1893/6) e no Boletim Eclesiástico (1902), ambos órgãos oficiais da Diocese de Mariana.
} 
A escrita eclesiástica veiculava a figura de sacerdotes que estivessem em consonância com o que a Igreja classificava como exemplar, logo, que seguiam um perfil de atuação no mundo e de santidade específicos do contexto institucional. A identidade clerical caracterizada em fins do século XIX e durante a primeira metade do XX dialogava com o modelo do "bom pastor"12. O sacerdote deveria portar-se como um "pastor das almas", mais flexível e preocupado com a espiritualidade e com a vida devota em favor do próximo, afastando-se da política e das práticas tidas pela Igreja como pecaminosas, assumindo uma postura conciliatória perante os conflitos da Igreja, da sociedade e dos fiéis. (BUARQUE; PIRES, 2012).

Nos periódicos oficiais da Diocese/Arquidiocese de Mariana, a construção de narrativas memorialísticas, apresentando sacerdotes considerados exemplares, era restrita a poucos clérigos da diocese mineira e do Brasil. Somente aqueles que ganharam importância notável na Diocese, devido ao modelo de vida e atuação, é que receberam narrativas elogiosas e mais longas nas páginas dos jornais. Descartando os bispos, poucos padres que atuavam no Brasil receberam um espaço narrativo considerável nos periódicos eclesiásticos, reduzindo-se a simples citações de seus nomes.

No âmbito internacional, podemos citar o padre João Maria Vianney, conhecido como o "santo cura d'Ars", nascido em Dardilly, França, em 1786, e falecido em Ars, em 1859. Foi beatificado em 1905, canonizado em 1925 e declarado padroeiro dos párocos em 1928. "Em paralelo, os documentos pontifícios passaram a apresentar João Maria Vianney, o cura d'Ars, beatificado em 1905, como o modelo do 'perfeito pastor de almas' (encíclica Haerent animo, ibid., p. 74)." (BUARQUE; PIRES, 2012, p. 63). O jornal Boletim Eclesiástico, de 1905, conferiu uma matéria especial a tal sacerdote, intitulada "O Cura d'Ars e o espírito da época", destinada à narrativização de parte de sua vida e trajetória eclesiástica exemplar (AEAM, 1905). Além disso, sua vida já havia sido biografada, anos após a sua morte, pelo cônego Francis Trochu ${ }^{13}$. Prática comum não somente nas dioceses francesas.

A consolidação das identidades eclesiais ultramontanas também foi realizada a partir da busca de padres exemplares do passado, como o cura d'Ars. Buscava-se no

\footnotetext{
12 "A espiritualidade do bom pastor emergiu, de maneira mais nítida, a partir da década de 1840, espraiando-se rapidamente por várias dioceses francesas. Tratava-se de uma piedade sacerdotal, conferidora de uma nova identidade a um clero que, embora tivesse sobrevivido à repressão desencadeada contra os eclesiásticos e os institutos religiosos, no contexto da Revolução Francesa, encontrava-se, por ocasião da Restauração de 1815, envelhecido e dividido." (BUARQUE; PIRES, 2012, p. 41).

${ }^{13}$ Sacerdote e historiador francês (1877-1967), reconhecido pelos seus textos biográfico-hagiográficos, sendo a obra sobre o Cura d'Ars o trabalho mais emblemático e reconhecido. (TROCHU, 1960, p. 7-9).
} 
passado artefatos para reafirmar identidades presentes, podendo resultar em novas construções identitárias (WOODWARD, 2000, p. 11), projetadas a partir de narrativas memorialistas feitas por leigos ou religiosos. A partir do final do século XIX, por meio da imprensa católica e de outros opúsculos regionais de cunho biográfico, os modelos locais passaram a ganhar maior importância e serem mais difundidos, sobretudo entre o clero $^{14}$. Podemos citar alguns desses opúsculos, de cunho biográfico, na Arquidiocese de Mariana, como a Vida de D. Antonio Ferreira Viçoso (1876), escrita pelo futuro arcebispo Silvério Gomes Pimenta, e a Vida de D. Silvério Gomes Pimenta (1927), escrita pelo bispo de Diamantina D. Joaquim, dentre muitas outras biografias eclesiásticas escritas redigidas nesse contexto (MICELI, 2009, p. 187-191).

Para servir de um modelo a ser seguido, foi preciso construir uma identidade sacerdotal unificada, que pode ser comparada com a construção da identidade de uma nação. Segundo Woodward, não há algo fixo e estabelecido, a priori, na identidade nacional. "Assim, essa redescoberta do passado é parte do processo de construção da identidade que está ocorrendo neste exato momento e que, ao que parece, é caracterizado por conflito, contestação e uma possível crise.” A própria identidade nacional, que tende a ser lida como mais fixa e unificada, é construída a partir de interesses e relações de poder, evocando imagens do passado que servem para a montagem da identidade que se quer elaborar. (WOODWARD, 2000, p. 12).

Seguindo esse mesmo modelo da espiritualidade do bom pastor, do qual Vianney era um representante emblemático, o sacerdote da Arquidiocese de Mariana, José Silvério Horta (1859-1933), considerado santo pela Igreja e pelo imaginário de seus contemporâneos, tornou-se um exemplo regional significativo de pastor das almas (BUARQUE; PIRES, 2012) $)^{15}$. Apesar de tais eclesiásticos terem obtido maior repercussão no imaginário de fins do século XIX e ao longo do XX, outros religiosos também ganharam nas biografias e nas páginas dos jornais oficiais textos sobre suas vidas e feitos tidos como elogiáveis e exemplares. Dentre eles, de significativa importância para a Diocese de Mariana, sobretudo por ter atuado como reitor do

\footnotetext{
${ }^{14}$ O jornal Boletim Eclesiástico (1902), órgão oficial da Diocese/Arquidiocese de Mariana, de tiragem mensal, tinha na lista de assinantes somente eclesiásticos, com raras exceções. Isso não exclui a possibilidade de leitura por leigos, mas denota a quem tais jornais eram endereçados. O periódico $\mathbf{O}$ Viçoso, por outro lado, tinha mais circularidade entre os leigos letrados.

${ }^{15}$ Para uma análise aprofundada da espiritualidade do bom pastor, relacionada à trajetória de Monsenhor José Silvério Horta, conferir a obra Monsenhor José Silvério Horta e a Espiritualidade do Bom Pastor (1859-1933) (BUARQUE; PIRES, 2012).
} 
seminário durante um longo tempo e no contexto da reforma ultramontana, está o lazarista João Batista Cornagliotto.

\section{João Batista Cornagliotto: a construção de um sacerdote exemplar}

João Batista Cornagliotto nasceu em Revigliasco, Itália, em 24 de junho de 1824, época conturbada, com eclosão de "revoluções sangrentas" e "reformas religiosas", vindo a ingressar em 1842 no Seminário Maior de Turim. Após quatros anos, formou-se em Teologia e, "reconhecendo em si uma vocação missionária" $(A E A M, 1909)^{16}$, solicitou sua admissão na Congregação da Missão, fundada em 1625 por são Vicente de Paulo. Enviado à Casa Matriz dessa Congregação em Paris, Cornagliotto foi ordenado presbítero em 15 de junho de 1848. Um ano depois, embarcou para o Brasil, juntamente com outros padres lazaristas franceses, em atendimento ao pedido do então bispo da Diocese de Mariana, D. Antônio Ferreira Viçoso (1844-1875). Cornagliotto foi inicialmente encaminhado ao Colégio de Campo Belo, onde atuou como diretor e professor de várias disciplinas; passados três anos, foi enviado ao Colégio da Bahia. Em 1854, foi chamado para assumir o cargo de Superior do Seminário de Mariana, oficialmente ocupado em $1856^{17}$. Segundo Dominique Julia, alguns seminários franceses, desde a segunda metade do século XVIII, já haviam sofrido um processo de reforma, ou seja, estavam em maior afinidade com as diretrizes romanas se compararmos com a situação eclesial da América Portuguesa (JULIA, 1997). Portanto, quando chegou ao Brasil, o missionário lazarista possuía uma formação mais ortodoxa, mais ligada ao catolicismo francês e, desse modo, mais próximo de Roma.

Sua função de reitor o tornava menos conhecido pela população, pois ficava muito tempo confinado no seminário realizando seus afazeres administrativos e educacionais. Seu projeto teológico-político e espiritual estava vinculado ao processo de reforma ultramontana da Igreja Católica em Minas Gerais, empreendido na Diocese de Mariana inicialmente pelo bispo Dom Viçoso (1844-1875). Em ocasiões especiais, como mostram os jornais oficiais da diocese, o padre Cornagliotto assumia em Mariana

\footnotetext{
${ }^{16}$ AEAM. Breve noticia histórica sobre a vida do Padre João Baptista Cornagliotto: sacerdote da Congregação da Missão. Superior do Seminário de Mariana., Arquivo 4, gaveta 2, pasta11. Este livreto biográfico foi publicado em 1909 por um padre da Congregação da Missão e relata a trajetória de vida do Pe. Cornagliotto.

${ }^{17}$ O padre Cornagliotto foi reitor dos Seminários de Mariana até 1902, contudo, esteve à frente do Maior somente quando esse retornou do Caraça, em 1882. (TRINDADE, 1953, p. 407).
} 
a função de pregador, abarcando temas referentes à conversão, santificação e salvação dos fiéis. Narrativas sobre a sua atuação e seu modelo exemplar de eclesiástico e pregador ganharam destaque nos órgãos oficiais:

\begin{abstract}
Até hoje tem sido de uma imparcialidade tão rara e tão isenta de acepção de pessoas, que nenhum aluno ou lente do Seminário, não digo que o acusasse, suspeitou sequer, ou duvidou ao menos de sua inteireza, retidão e equidade. E coisa notabilíssima, com os diversos atos de rigor que ele tem praticado para manter a disciplina nestes 40 anos, se tem feito descontentes, não fez um só inimigo.

Já os homens verdadeiramente de bem, que se tem formado à sua sombra, sacerdotes e seculares, pais de família, professores, médicos, advogados, fora tarefa difícil numerar. Contentamo-nos com dizer esta verdade, reconhecida por nossa experiência. Os homens educados o Seminário de Mariana nestes 40 anos, em todos os lugares onde estão e em todas as posições que ocupam, têm sobre outros em iguais condições um cunho de superioridade, que os torna sempre distintos. Ainda os que se extraviam, conservam alguma coisa daquela educação sã e robusta, que não se pode perder de todo.

Além destes dotes possui o Sacerdote de que nos ocupamos outros não menos raros. É um pregador de primeira ordem; e podemos dizer que, apesar de não ser de todo correta a sua linguagem, por ser estrangeiro, em Mariana e em Minas não houve ainda maior pregador, nem mais perfeito orador sagrado. É um sacerdote de caridade e de zelo pelo bem das almas, como verdadeiro missionário. Deste zelo dão testemunhos as obras por ele compostas e publicadas, algumas das quais, como o Thesouro do Christão, têm contado sucessos raríssimos em obras deste gênero no Brasil, e são todas cunhadas com o selo de profundo saber.

Não desceremos a suas virtudes particulares, que não queremos ser seu panegirista: limitamo-nos ao que é público, e de todos conhecido. (AEAM, $1893^{18}$ - Grifos nossos).
\end{abstract}

Em 1902, aos 79 anos, João Batista Cornagliotto pediu demissão do cargo de reitor, por motivos de fadiga, velhice e saúde debilitada (TRINDADE, 1953, p. 414415). Após sua demissão, o padre Cornagliotto conservou-se nos aposentos do Seminário até a sua morte. Seu envolvimento político foi raro, como podemos constatar com a análise da documentação levantada. Devido ao seu cargo de reitor, ficou mais envolto em questões de ordem administrativa, educacional e espiritual (como pregador e confessor nos retiros do clero), tornando-se um padre exemplar na concepção de seus companheiros eclesiásticos - um sacerdote conciliador, preocupado com o pastoreio das almas, afastado da política e das práticas tidas pela Igreja Católica como pecaminosas. O Boletim Eclesiástico, de 1902, órgão oficial da Diocese de Mariana, enalteceu a figura e trajetória do padre Cornagliotto quando ele se afastou da reitoria do Seminário:

Depois de quase meio século de serviços relevantíssimos prestados a esta diocese, principalmente como Reitor do seminário episcopal desta cidade de

${ }^{18}$ ARQUIVO ECLESIÁSTICO DA ARQUIDIOCESE DE MARIANA (AEAM). O Viçoso. Armário 1, Prat. 4, Mariana, 6/1893. 
Mariana, obteve a exoneração deste cargo e despediu-se desta cidade este ilustre filho da Congregação da Missão de S. Vicente de Paula o revd. Padre Cornagliotto. Quanto era aqui estimado e venerado, e quanto pesar e saudades deixou a sua despedida nos corações dos Marianenses, principalmente no coração do Exmo. Sr. Bispo, assaz o demonstra a carta de S. Exc. Rvma., que publicamos em outro lugar, dirigida ao Rvmo. Padre Visitador da Congregação.

Enviamos ao venerando e amado ancião Rvdmo P. Cornagliotto as nossas saudades e os nossos votos.

Carta do Bispo D. Silvério: Por esta carta, que vai estampada com licença do Exm. Sr. Bispo de Mariana, sabemos que o venerado Padre João Baptista Cornagliotto, ilustre sacerdote da Congregação da Missão e estimado Reitor do nosso Seminário, pediu ultimamente a sua exoneração deste cargo, para descansar à sombra de suas esclarecidas virtudes, dos inúmeros serviços e benefícios prestados a esta diocese, que hoje de joelhos a seus pés, lamenta, resignada com os insondáveis arcanos da Providência, a sua retirada. É certo que este claro tão profundamente aberto nos destinos econômicos de uma administração toda cheia de fecundos resultados, será dificilmente preenchido, se Deus apartar de nós a sua mão protetora, assinalando-nos outro que não queira seguir as pisadas gloriosas do Padre Superior, cujo nome imortal há de perdurar sempre no coração do povo mineiro. Eis a carta: "J.M.J. - Mariana, 8 de Julho de 1902. Rvm. Sr. Padre Visitador Pedro Dehaine. Tenho presente a carta de V. Rvm. de 27 de Junho último em que me comunica haver o Rvd. Padre Cornagliotto pedido com insistência exoneração do cargo de Reitor do nosso Seminário por causa de sua idade e achaques, não tendo V. Rvm. animo de insistir com ele para continuar por essas mesmas razões. Respeitando a determinação de V. Rvm. resigno-me com esta exoneração que vai encher de mágoa o clero em geral, e ainda grande parte de fiéis que por espaço de quase 50 anos receberão deste Varão raro educação solidamente cristã, exemplos de virtude achrisolada, e benefícios espirituais assinalados no púlpito, na imprensa, na direção da consciência e especialmente a diocese na administração admirável do seu Seminário nesse longo período de meio século. Aproveitando esta ocasião para mais uma vez externar meu reconhecimento pelos serviços eminentes prestados por este filho de S. Vicente ao Seminário, a diocese e a mim peço a Deus que o sucessor do Padre Cornagliotto possa acompanhá-lo ainda com alguma distância no tino administrativo e na copia de benefícios com que, por meio dele, nos mimoseou a Divina Providência. - D. V. Rvm. humilde servo - + Silvério, Bispo de Mariana. (AEAM, 1902, p. 20-21; p. $29^{19}-$ Grifos nossos).

O perfil sacerdotal encampado por João Batista Cornagliotto, inspirado no modelo do "bom pastor" 20 , pressupunha um padre preocupado com o "zelo pelo bem das almas", com a ajuda ao próximo (no atendimento espiritual, educacional e caritativo), embasado numa "educação solidamente cristã". O padre deveria ser um exemplo, para o clero e para a sociedade, de uma pessoa pautada na "inteireza, retidão e equidade". Para tanto, deveria se dedicar com plenitude ao ofício eclesiástico (como pregador ou reitor), à vida devota e ao pastoreio dos fiéis. Além disso, ele foi reconhecido devido ao seu bom desempenho como administrador das finanças do

${ }^{19}$ ARQUIVO ECLESIÁSTICO DA ARQUIDIOCESE DE MARIANA. Jornal Boletim Eclesiástico, ano II, n. 1, 1902. p. 20-21; p. 29.

${ }^{20} \mathrm{Ou}$ "pastor das almas". 
Seminário, conseguindo manter muitos alunos carentes que não tinham condições de pagar as mensalidades (PIRES, 2010).

A documentação eclesiástica, principalmente a imprensa católica, não só veiculou aspectos de sua trajetória e atuação, mas criou uma memória positiva do padre Cornagliotto, certamente por ele estar em afinidade com o que a Igreja Católica considerava, na época, ser exemplar, digno de enaltecimento. Seu reconhecimento posterior se deve, em grande parte, à constituição narrativa de sua memória. Ele tornouse um emblema do sacerdote reformado na Diocese de Mariana por meio da construção positiva de sua memória e identidade, enaltecidas em periódicos e na biografia escrita sob anonimato por um padre lazarista. ${ }^{21}$

Já era eminente o seu falecimento, em princípios de abril de 1907, devido à hipertrofia do coração da qual sofria. Recebeu a Extrema Unção em 23 de junho de 1907, vindo a falecer no dia 23 de julho do mesmo ano. O padre João Batista Cornagliotto morreu aos 83 anos, com 60 de vocação, dos quais passou 54 anos no Seminário de Mariana, sendo durante 46 anos reitor do mesmo. Em gratidão ao padre, o Dr. João Pinheiro da Silva, então presidente do Estado, ofereceu sua lápide tumular, localizada na Capela do Seminário de Nossa Senhora da Boa Morte, em Mariana, onde permanece até hoje (TRINDADE, 1953, p. 425).

Estes ossos amados coberto por pedras / / João B. Cornagliotto / / Padre da Congregação da Missão / / Por quase meio século regeu este Seminário Marianense maravilhosamente, reforçando-o em cultura, piedade e beleza / / Defensor da cultura e piedade exemplar / / Seguidor tenaz da justiça / / O Governo e a Igreja se enriqueceram com ele// Nascido em 3 de junho de 1824// Morreu em 10 de julho de $1907 .{ }^{22}$ (Tradução de Julia Rany Campos Uzun).

Tal leitura de Cornagliotto, positivada pela Igreja Católica em narrativas memorialistas e biográficas, pode ser entendida apenas como uma ficção de si, voltada

\footnotetext{
${ }^{21}$ As obras do padre Cornagliotto eram escritas sob o anonimato, assinadas com a seguinte inscrição: "por um padre da Congregação da Missão". Tal inscrição aparece no opúsculo biográfico Breve noticia historica sobre a vida do Padre João Baptista Cornagliotto..., logo, pode ter sido escrito pelo próprio Cornagliotto.

${ }^{22}$ Hoc conteguntur lapide dilecti ossa // Joannis B. Cornagliotto// Congregationis Missionis Sacerdotis // medio feresoeculo Seminarium hoc Mariannense mirifice rexit, auxit, ornavit // pietatis cultur et fautor eximus // justitiae sectator tenacissimus // Rempublican et Ecclesiam praestantibus ditavit viris // Natus III Idus Junni anno 1824 // Obiit X Kalendas Augusti 1907.
} 
para a consolidação de uma memória "sem manchas" e de uma identidade ultramontana unificada na concepção do bom pastor? Acreditamos que não. A construção de um sacerdote exemplar, apesar de contar com a dimensão poético-ficcional para a sua elaboração, não se restringe ao nível discursivo, pois, se assim fosse, todos poderiam se tornar exemplares. Cornagliotto foi construído como exemplar, porém não aleatoriamente. Sua postura condizia, ainda que não de maneira impecável, com o que era esperado de um sacerdote reformado.

A escrita eclesiástica dos jornais e das biografias não é exclusivamente uma prática ficcional. Podemos pensá-la como um processo de representação/construção do sujeito e de sua identidade, e não como uma ficção do eu, lembrando que só é possível definir uma identidade e um sujeito unificados e exemplares por meio da narrativa (RICOEUR, 1991, p. 138). Nas narrativas memorialistas eclesiásticas, essa harmonia entre o ipse e o idem, ou entre história de vida e imaginação, fica mais evidente e é utilizada para produzir um sujeito mais coerente e, consequentemente, uma identidade unificada e exemplar voltada para a consolidação do projeto eclesial da reforma ultramontana. Tal conotação harmônica não é tão evidente nas cartas escritas pelo padre Cornagliotto, até porque as cartas não necessitam apresentar um sujeito unificado e exemplar, pois visam à comunicação, pautada na intimidade estabelecida entre o remetente e o destinatário. Diferentemente das narrativas memorialistas e biográficas sobre o padre Cornagliotto, seu epistolário apresenta um sujeito cindido pelas incertezas e paixões da vivência humana, superadas pela crença no sagrado:

Depois de ter sido enviado, sucessivamente, a Congonhas, ao Caraça e à Mariana, eis o quê, Senhor e muito prezado Confrade, eis que o bom Deus tem exigido de mim! Oh! Como a vida do homem é mutável e incerta! É com grande razão que se compara tais dias fugidios a um mar agitado pelo vento, no tumulto de uma noite de tempestade! Se eu olho ao redor, tudo me parece como um sonho; se eu considero o presente, eu tenho dificuldade de compreender a mim mesmo; mas eu sinto que meu espanto e minha inquietude redobram ainda mais quando eu quero interrogar-me sobre o meu futuro.

Não creiais, entretanto, que eu sucumbo sob a angústia, nem que eu perco a coragem. Oh! Não, ao contrário, é no presente, quando eu sou mais premido pelos meus deveres e pela dificuldade de os cumprir, que eu mais me confio ao socorro do Altíssimo. Eu medito com consolação nessas belas palavras de são Paulo: Eu tudo posso naquele que me fortalece. O que seria impossível ao homem de realizar, abandonado apenas a suas forças, torna-se fácil para ele, uma brincadeira, quando a graça o sustenta. (CONGREGATION OF THE 
MISSION - VINCENTIAN JOURNALS AND PUBLICATIONS, DEPAUL UNIVERSITY, 1851). ${ }^{23}$

O fortalecimento da Igreja Católica, por meio da construção e da afirmação da identidade do sacerdote reformado nas narrativas memorialísticas, foi uma estratégia voltada, antes de tudo, aos próprios eclesiásticos. É uma escrita produtora de identidade e sentido para a própria instituição Igreja. É uma escrita que edifica, um ato de $\operatorname{crer}^{24}$, para lembrar e seguir.

\section{Um sujeito sempre cindido: considerações finais}

As leituras ricoeurianas nos fornecem uma chave de leitura complementar às proposições de Kathryn Woodward para se pensar a formação da identidade sacerdotal em fins do século XIX e início do XX, na medida em que Ricoeur considera o sujeito cindido não como produto apenas da pós-modernidade e apresenta a narrativa como uma maneira de equilíbrio entre a identidade-idem e a identidade-ipse. A identidade do sacerdote reformado deveria ser exemplar. Para tanto, foi imprescindível o uso da narrativa, a fim de construir as histórias de vida dos sacerdotes ultramontanos exemplares e, dessa forma, construir identidades unificadas em torno de um ideal de santidade e postura clerical.

A dimensão ambígua, contraditória e caótica da vivência humana impede o encontro entre mesmidade e ipseidade, impossibilitando a construção de um si-mesmo perfeito, modelar, santo. Os santos "são as suas histórias. Desse ponto de vista, fazer santos é um processo pelo qual uma vida é transformada em um texto" (WOODWARD, 1992, p. 18). Canonicamente, um sacerdote só se torna santo quando morre. Isso faz sentido, pois somente quando a existência desaparece e a vida se organiza numa narrativa é que o sujeito é capaz de se tornar coerentemente santo, exemplar. A vida dos sacerdotes e a consequente identidade construída só poderiam ser santas, unificadas e exemplares no plano narrativo, pois uma vida sem "mácula", sem "manchas" é possível

\footnotetext{
${ }^{23}$ CONGREGATION OF THE MISSION - VINCENTIAN JOURNALS AND PUBLICATIONS, DEPAUL UNIVERSITY. Carta do Sr. Cornagliotto ao Sr. Martin, diretor do Seminário da Congregação da Missão, em Paris. Campo Belo, 3 de março de 1851. In: Annales de la Congrégation de la Mission Tomo XV. Ecrites par les Prèlres de cette Congrégation employés dans les Missions éirangères. Paris: Imprimerie D'adrien Le Clere Et Cie.

${ }^{24} \mathrm{O}$ ato de crer é entendido por Michel de Certeau como o "investimento das pessoas em uma proposição, $\mathrm{o}$ ato de enunciá-la considerando-a verdadeira - noutros termos, uma 'modalidade' da afirmação" (CERTEAU, 1998, p. 278).
} 
somente no plano da escrita, num diálogo entre história e ficção, entre vida e imaginação, entre mesmidade e ipseidade. $\mathrm{O}$ sacerdote se torna exemplar quando sua vida é transposta e construída na escrita eclesiástica - em periódicos oficiais, hagiografias, biografias e autobiografias religiosas ou em outros estilos narrativos. 
Identity, modernity and ecclesiastical written in times of Ultramontane Reform: theoretical notes from the contributions of Paul Ricoeur and Kathryn Woodward

\begin{abstract}
This article aims to analyze forms of production of identity in modernity from the symbolic constructions present in memoirists narratives written by the Catholic Church in the late nineteenth and early twentieth centuries. Discusses some theoretical paths outlined by Paul Ricoeur and Kathryn Woodward to understand how such identities are constructed and designed, following a theological-political project to strengthen the institution, founded on the development of exemplary priests and saints. We seek to relate such theoretical premises with the study of ecclesiastical writing in Brazil, particularly in Minas Gerais, used to consolidate the ultramontane reform process in vogue in Catholicism in Brazil. We used as the object of analysis the figure of a priest constructed as exemplary by the official journals of the Diocese of Mariana, the cleric and rector of the seminary João Batista Cornagliotto (1855-1902).
\end{abstract}

Keywords: Identity; Ecclesiastical Writing; Catholicism; Ultramontanism.

\title{
REFERÊNCIAS
}

\section{Fontes primárias}

ARQUIVO ECLESIÁSTICO DA ARQUIDIOCESE DE MARIANA. Breve noticia histórica sobre a vida do Padre João Baptista Cornagliotto: sacerdote da Congregação da Missão. Superior do Seminário de Mariana. AEAM, Arquivo 4, gaveta 2, pasta11, 1909.

ARQUIVO ECLESIÁSTICO DA ARQUIDIOCESE DE MARIANA. O Viçoso. Armário 1, Prat. 4, AEAM, Mariana, 6/1893.

ARQUIVO ECLESIÁSTICO DA ARQUIDIOCESE DE MARIANA. Boletim Eclesiástico. Ano II, n.1, 1902. p. 20-21; p.29.

CARTA do Sr. Cornagliotto ao Sr. Martin, diretor do Seminário da Congregação da Missão, em Paris. Campo Belo, 3 de março de 1851. In: Annales de la Congrégation de la Mission - Tomo XV. Ecrites par les Prèlres de cette Congrégation employés dans les Missions éirangères. Paris: Imprimerie D'adrien Le Clere Et Cie. In: Congregation of the Mission - Vincentian Journals and Publications. Volume 16, 1851. DePaul University. 
Fontes secundárias

A Bíblia de Jerusalém. São Paulo: Paulus, 1996.

BAUMAN, Zygmunt. Modernidade líquida. Rio de Janeiro: Jorge Zahar, 2001.

BUARQUE, Virgínia; PIRES, Tiago. Monsenhor José Silvério Horta e a espiritualidade do Bom Pastor. Belo Horizonte: Fino Traço, 2012.

CERTEAU, Michel de. A Escrita da História. Rio de Janeiro: Forense Universitária, 2008.

CERTEAU, Michel de. Credibilidades políticas. In: CERTEAU, Michel de. A invenção do cotidiano: artes de fazer. 3 ed. Petrópolis: Editora Vozes, 1998.

GIDDENS, Anthony. As consequências da modernidade. São Paulo: Ed. UNESP, 1991.

GUMBRECHT, Hans Ulrich. Cascatas da Modernidade. In: GUMBRECHT, Hans Ulrich. Modernização dos sentidos. São Paulo: Ed. 34, 1998.

HALL, Stuart. A identidade cultural na pós-modernidade. 4 ed. DP\&A, 2000.

JULIA, Dominique. O Sacerdote. In: VOVELLE, Michel. O homem do Iluminismo. Lisboa: Editora Presença, 1997.

KOSELLECK, R. Futuro Passado: contribuição à semântica dos tempos históricos. Rio de Janeiro: Contraponto: Ed. PUC-Rio, 2006.

MICELI, Sergio. A elite eclesiástica brasileira. São Paulo: Companhia das Letras, 2009.

OLIVEIRA, Gustavo de Souza. Entre o rígido e o flexível: D. Antônio Ferreira Viçoso e a reforma do clero mineiro (1844-1875). 2010. Dissertação (Mestrado em História) Universidade Estadual de Campinas, Programa de Pós-graduação em História, Campinas.

OLIVEIRA, Luciano Conrado; MARTINS, Karla Denise. O ultramontanismo em Minas Gerais e em outras regiões do Brasil. Revista de C. Humanas, Viçosa, v. 11, n. 2, p. 259-269, 2011.

PASQUIER, Padre Eugênio (obra póstuma). Os Primórdios da Congregação da Missão no Brasil e a Companhia das Filhas da Caridade: 1849-1866. Vol. II. Belo Horizonte: Companhia das Filhas da Caridade, [19--].

PIRES, Tiago. O discurso do Padre João Cornagliotto, 1855-1902: desafios do catolicismo frente à modernidade. In: III Simposio Internacional sobre Religiosidad, Cultura y Poder (III SIRCP). Actas del III Simposio Internacional sobre Religiosidad, Cultura y Poder. Buenos Aires: Patrícia Fogelman, 2010. 
PIRES, Tiago. A coroa para o céu: o modelo de Igreja e sacerdote no discurso do padre João Batista Cornagliotto (1855-1902). 2012. Monografia (Graduação em História) - Universidade Federal de Ouro Preto, Departamento de História, Ouro Preto.

PIVA, Edgar Antônio. A questão do sujeito em Paul Ricoeur. Síntese - Revista de Filosofia, v.26, n. 85, p. 205-237, 1999.

RICOEUR, Paul. O si-mesmo como um outro. Campinas: Papirus, 1991.

SESBOUÉ, Bernard; THEOBALD, Christoph. História dos dogmas. A Palavra da salvação (séculos XVIII - XX). T. 4. São Paulo: Loyola, 2006.

SPERBER, Suzi Frankl. O diálogo entre mesmidade (identidade genética) e a ipseidade, responsável pela ética - ou, de uma alteridade constitutiva da responsabilidade na relação Eu-Tu. Revista Eletrônica Carrelatio, v.8, n.15, p.5-15, jun., 2009. Disponível em: <https://www.metodista.br/revistas/revistas-metodista/index.php/COR/article/view /967/1011>. Acesso em: 2 nov. 2012.

TRINDADE, Raymundo, cônego. Arquidiocese de Mariana: subsídios para sua história - I Volume. $2^{a}$ edição. Belo Horizonte: Imprensa Oficial, 1953.

TROCHU, Francis. O Cura d'Ars. São João Batista Vianney (1786-1859). Petrópolis: Editora Vozes, 1960.

VERGOTE, Antoine. Modernidade e cristianismo: interrogações e críticas recíprocas. São Paulo: Loyola, 2002.

WOODWARD, Kathryn. Identidade e diferença: uma introdução teórica e conceitual. In: SILVA, Tomaz Tadeu da; HALL, Stuart; WOODWARD, Kathryn (Org.). Identidade e diferença: a perspectiva dos estudos culturais. Petrópolis; Rio de Janeiro: Editora Vozes, 2000. 